\title{
Silicones para próteses faciais: efeito da desinfecção química sobre dimensão e superfície - Parte II
}

\section{Facial prosthesis silicones: desinfection effect about dimension and surface - Part II}

\author{
Aimée Maria GUIOTTI \\ Mestranda - Programa de Pós-Graduação em Prótese Dentária - Faculdade de Odontologia de Araçatuba - \\ UNESP \\ Marcelo Coelho GOIATO \\ Professor Assistente - Departamento de Materiais Odontológicos e Prótese - Colaborador da Disciplina de \\ Oclusão - Faculdade de Odontologia de Araçatuba - UNESP
}

\begin{abstract}
Resumo
O objetivo desta pesquisa foi avaliar a influência da desinfecção química sobre a estabilidade dimensional e a manutenção de detalhes de um silicone para uso facial. Os corpos-de-prova foram confeccionados com uma matriz, de acordo com a especificação no 19 da A. D. A. e a revisão ISO 4823:1984 para materiais de moldagem elastoméricos não-aquosos, sendo divididos em 3 grupos: controle (incolor), pigmentado com maquiagem e com óxido de ferro, analisados sem a ação da desinfecção e sob a ação da desinfecção química. Os corpos-de-prova foram observados em microscópio comparador, para a verificação da alteração dimensional e em lupa estereoscópica, para a análise da reprodução de detalhes. Essas leituras foram realizadas imediatamente, trinta e sessenta dias após a polimerização dos corpos-de-prova, com e sem desinfecção química. Os dados foram submetidos à análise estatística, pelo teste de Tukey, em nível de 5\% de probabilidade. A desinfecção química somente alterou dimensionalmente o grupo Silastic com maquiagem, porém esta contração foi inferior à recomendada pela $\mathrm{A}$. D. A. Pôde-se concluir que a clorexidina não promoveu alterações significativas ao material. A fidelidade e manutenção da reprodução de detalhes obtida para todos os corpos-de-prova não foi influenciada pela ação da desinfecção química.
\end{abstract}

\section{UNITERMOS}

Prótese maxilofacial; elastômeros de silicone; prótese dentária, estabilidade dimensional, desinfecção

\section{INTRODUÇÃO}

Quando da contra-indicação ou impossibilidade do tratamento plástico-cirúrgico, o único recurso para a recuperação estética e funcional do mutilado da face é o tratamento protético. Dentre os fatores que condicionam o sucesso de uma prótese facial, destacam-se as propriedades do material utilizado na sua confecção (REZENDE26, 1975).

A busca por materiais mais aceitáveis, para substituir as estruturas faciais perdidas, tem aumentado grandemente nas últimas décadas. Esse aumento é devido ao desenvolvimento da indústria de materiais e à diminuição da mortalidade após tratamento do câncer de cabeça e pescoço. Os materiais para próteses faciais deveriam possuir as seguintes características: biocompatibilidade; re- sistência; durabilidade; peso leve; resistência aos agentes químicos e do meio ambiente; facilidade de manipulação, fabricação e limpeza; aparência agradável e textura natural (MOORE et al. ${ }^{18}$, 1977; REZENDE \& MARINGONI FILHO ${ }^{25}, 1979$; LEWIS \& CASTLEBERRY $\left.{ }^{15}, 1980\right)$.

A procura por um material ideal, para a reabilitação protética de pacientes com desfiguração ou deformações faciais, existe desde os primórdios da história. As formas mais primitivas de próteses faciais eram construídas em madeira, marfim, ceras e metais (ANDRES et al. ${ }^{1}, 1992$ ). Atualmente, as possibilidades de reconstrução protética encontram-se aumentadas pelo freqüente surgimento de materiais capazes de substituir os componentes faciais ausentes, como as resinas acrílicas, poliuretanos, cloretos polivinílicos, polietilenos e silico- 
nes (AZAMBUJA et al. ${ }^{3}, 1994$; LEWIS \& CASTLEBERRY $\left.{ }^{15}, 1980\right)$.

Embora o silicone estivesse comercialmente disponível após a Segunda Guerra Mundial, seu uso médico iniciou-se em 1953. Entretanto, o silicone elastomérico foi primeiramente utilizado para próteses faciais por Barnhart ${ }^{4}$ em 1960 e, desde então, tornou-se o material de escolha devido às suas propriedades químicas inertes, resistência, durabilidade e facilidade de manipulação (ANDRES et al. ${ }^{1}$, 1992). O silicone é o material que mais se aproxima do ideal, ainda que tenha custo elevado e difícil aquisição em nosso país, pois a maioria é de fabricação estrangeira (SCHAAF ${ }^{28}, 1970$; NEVES \& VILLELA $\left.{ }^{19}, 1998\right)$.

A limitação do emprego do silicone, como material para a confecção das próteses faciais, é a sua rápida degradação e instabilidade de cor (LEMON et al. ${ }^{14}$, 1995). Para Ishigami et al. ${ }^{11}$ (1997), as próteses confeccionadas com silicones elastoméricos são consideradas efetivas por apenas seis meses a um ano, havendo a necessidade de serem refeitas devido à instabilidade de cor, à deterioração da textura e das margens e à diminuição da resistência das próteses, em função dos efeitos dos raios ultravioletas, da poluição do ar, das mudanças de temperatura e umidade, da deposição de resíduos microscópicos nas porosidades da superfície, uso de adesivos e manuseamento e limpeza contínua das próteses pelo paciente.

Em se tratando de próteses faciais, a deficiência na higienização das mesmas colabora para que os tecidos subjacentes a essas próteses fiquem susceptíveis às infecções. Portanto, é de fundamental importância o procedimento de desinfecção química das próteses, com soluções desinfetantes não irritantes, garantindo a manutenção da saúde dos tecidos que entrarão em contato com as mesmas.

A clorexidina é uma substância química introduzida, há muitos anos, como desinfetante de largo espectro contra bactérias Gram+ e Gram- (DE$\mathrm{NARDI}^{8}$, 1994). Seu uso em Odontologia iniciou-se como desinfetante de campo cirúrgico e de canais radiculares. A droga apresenta uma baixa toxidade e não têm sido relatadas alterações teratológicas e nem a presença de produtos catabólitos cancerígenos ou de retenção permanente da droga no organismo (DENARDI $\left.{ }^{8}, 1994\right)$. Não existem relatos de efeitos tóxicos após a ingestão de clorexidina e, em seus muitos anos de uso, raros casos de sensibilidade foram registrados, confirmando a ausên- cia de toxidade e oncogenicidade da clorexidina (ROWE \& FORREST ${ }^{27}, 1978$ ). A clorexidina tem sua ação desencadeada em 15 segundos e efeito residual de 6 horas, não sendo significativamente afetada pela presença de sangue e outras matérias orgânicas (LARSON ${ }^{13}, 1988$ ).

$\mathrm{Na}$ primeira parte deste estudo foi analisada a influência dos pigmentos e do tempo de exposição ao meio ambiente sobre a estabilidade dimensional e a manutenção de detalhes de dois silicones nacionais de uso industrial, visto que estes materiais possuem a mesma composição básica dos silicones específicos para a confecção de próteses faciais, cujo custo é muito alto e de difícil aquisição em nosso país, pois a maioria é de fabricação estrangeira.

Propusemo-nos, nesta publicação, a estudar a influência da desinfecção química sobre a estabilidade dimensional e a manutenção de detalhes do mesmo silicone nacional de uso industrial - o Silastic 732 R.T.V., já que este material mostrou-se estável dimensionalmente e com fidelidade de reprodução de detalhes em função da pigmentação e do envelhecimento, variáveis estas, analisadas no estudo anterior.

\section{Material e Método}

\section{Material}

Considerando os resultados obtidos em pesquisa prévia, o material utilizado neste estudo foi o silicone acético de fabricação nacional desenvolvido para uso industrial, cuja composição básica é semelhante ao dos silicones específicos para prótese facial (Quadro 1 - Figura 1) - o Silastic 732 R.T.V. Este material foi analisado em estudo anterior quanto à influência do tempo de exposição ao meio ambiente e da pigmentação, em que ele apresentou propriedades adequadas.

\section{Método}

A especificação no 19 da A.D.A. ${ }^{23}$ (1977) e a revisão ISO 4823:198424 (1989) para materiais de moldagem elastoméricos não aquosos foram usadas como normas para os testes efetuados com os silicones de uso industrial. A matriz utilizada para a confecção dos corpos-de-prova, que foram submetidos aos testes de alteração dimensional linear e manutenção da reprodução de detalhes, é composta por uma matriz cilíndrica metálica e uma moldura metálica em forma de anel (Figura 2). 
Guiotti AM, Goiato MC

SILICONES PARA PRÓTESES FACIAIS: EFEITO DA DESINFECÇÃO QUÍMICA SOBRE DIMENSÃO E SUPERFÍCIE - PARTE II

Quadro 1 - Silicones para uso em prótese facial (Figura 1)

\begin{tabular}{|c|c|c|c|c|c|}
\hline MATERIAL & $\begin{array}{c}\text { TIPO DE REAÇÃO } \\
\text { DE POLIMERIZAÇÃO }\end{array}$ & FABRICANTE & CIDADE & $\begin{array}{c}\text { LOTE } \\
\text { BÁSICA }\end{array}$ \\
\hline $\begin{array}{l}\text { SILASTIC } \\
\text { 732 R.T.V. }\end{array}$ & CONDENSAÇÃO & $\begin{array}{c}\text { DOW CORNING } \\
\text { do Brasil Ltda. }\end{array}$ & SÃO PAULO - SP & $\begin{array}{c}6466091 \\
\text { POLIDIMETIL- } \\
\text { SILOXANO }\end{array}$ \\
\hline
\end{tabular}

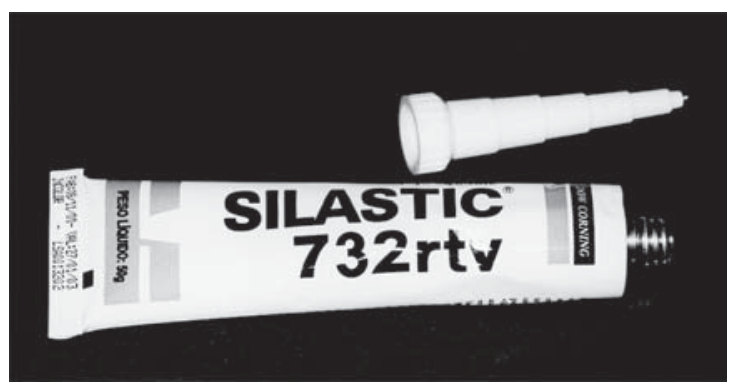

FIGURA 1 - Silicone industrial - Silastic 732 R.T.V.
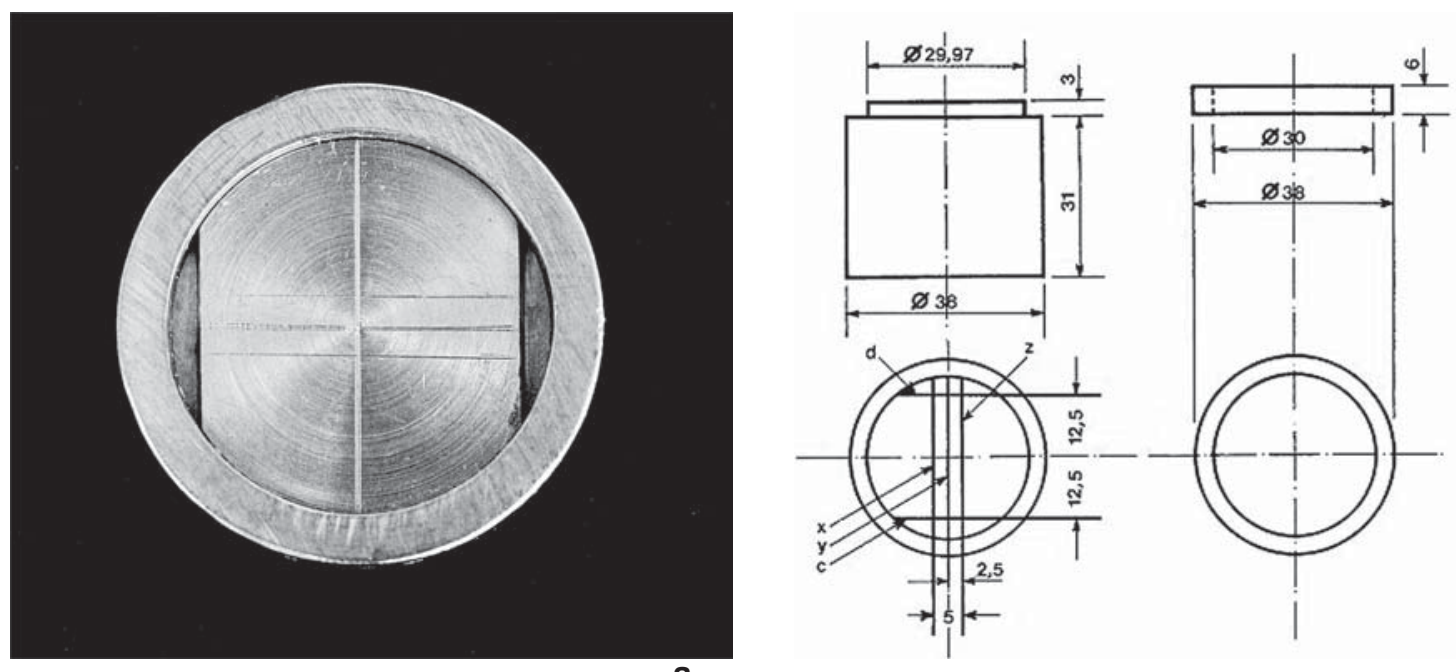

b

FIGURA 2 - Matriz utilizada: a) matriz metálica, b) desenho esquemático da matriz.

O método utilizado neste trabalho foi o mesmo do estudo anterior, em que o silicone foi manuseado de acordo com as instruções do fabricante, em temperatura ambiente de $23 \pm 2^{\circ} \mathrm{C}$ e umidade relativa de $50 \pm 10 \%$, com e sem pigmentos (grupo controle).
O material ficou confinado no interior da matriz com a superfície externa exposta ao meio ambiente durante 24 horas, pois a liberação de ácido acético é estabilizada 24 horas após o início do processo de polimerização, conforme as recomendações dos fabricantes. Após esse período, cada 
corpo-de-prova foi separado cuidadosamente da matriz metálica (A), para evitar distorções.

Portanto, foram confeccionados trinta corposde-prova, sendo divididos em 3 grupos: sem pigmentação, pigmentados com pó de maquiagem e pigmentados com óxido de ferro, que foram avaliados sem a ação da desinfecção e sob a ação da desinfecção química (Figura 3).

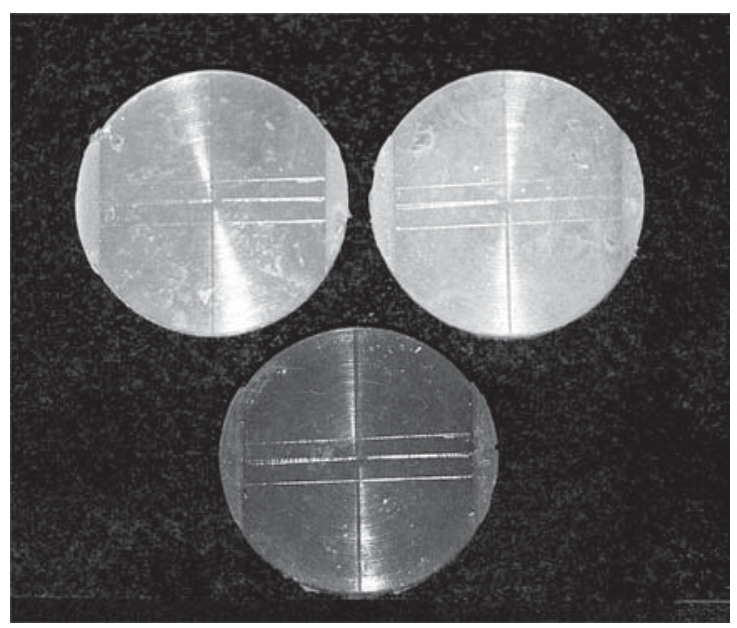

FIGURA 3 - Corpos-de-prova.

\section{Procedimento do Teste para Avaliar a Alteração Dimensional Linear em Função Da Desinfecção Química}

Nos grupos sem desinfecção, as leituras dos corpos-de-prova foram realizadas imediatamente, trinta dias e sessenta dias após a separação deles da matriz metálica. Este período de tempo de sessenta dias é freqüentemente o tempo esperado para se realizar o controle dessas próteses faciais pelo profissional. Os corpos-de-prova permaneceram armazenados em recipiente de plástico sem tampa, sobre uma bancada, em ambiente com temperatura não controlada durante todo o período experimental, simulando as condições clínicas em que estas próteses se mantêm durante seu uso clínico pelos pacientes, ou seja, em contato com o meio ambiente.
Para os grupos que receberam desinfecção, o desinfetante eleito para o teste foi o digluconato de clorexidina a 2\% (FGM Produtos Odontológicos - Joinville S.C.), que foi aspergido sobre os corpos-de-prova por meio de um borrifador (Figura 4), imediatamente após a separação destes da matriz metálica, agindo por 1 minuto, de acordo com as instruções do fabricante. Após o período de desinfecção, os corpos-de-prova foram lavados em água corrente e secos com jato de ar. Este procedimento foi repetido diariamente e as leituras foram efetuadas também na mesma seqüência: imediatamente, trinta dias e sessenta dias após a desinfecção diária. Este procedimento foi realizado para simular a higienização e desinfecção da prótese facial pelo paciente.

Para todos os grupos, os corpos-de-prova ficaram sobre a bancada, recebendo luminosidade artificial, porém sem a incidência de luz natural direta.

Todas as leituras dos corpos-de-prova foram realizadas com o auxílio do microscópio comparador Carl Zeiss (Alemanha), com precisão de 0,01milímetros.

A alteração dimensional dos silicones ensaiados para uso facial foi calculada utilizando-se a fórmula abaixo, expressa em porcentagem (\%):

$$
\text { Alteração dimensional } \%=\frac{(\mathrm{B}-\mathrm{A}) \times 100}{\mathrm{~A}}
$$

$\mathrm{A}=$ distância original da matriz, entre as bordas $\mathrm{C}$ e $\mathrm{D}=25 \mathrm{~mm}$

$\mathrm{B}=$ distância entre as bordas $\mathrm{C}$ e $\mathrm{D}$, nos corposde-prova no período inicial, trinta dias e sessenta dias.

\section{Procedimento do Teste para Avaliar a Manutenção da Reprodução de Detalhes em Função da Desinfecção Química}

Todos os corpos-de-prova usados no teste para avaliar a alteração dimensional linear foram utilizados para o teste de manutenção da reprodução de detalhes. A análise foi feita nos corpos-de-prova em função da reprodução dos três sulcos contidos na matriz metálica (A), com larguras de $20 \mu \mathrm{m}$, $50 \mu \mathrm{m}$ e $75 \mu \mathrm{m}$. Os detalhes de reprodução foram observados por uma lupa estereoscópica Olympus Tokyo, com baixo ângulo de iluminação, num aumento de 13 vezes. 


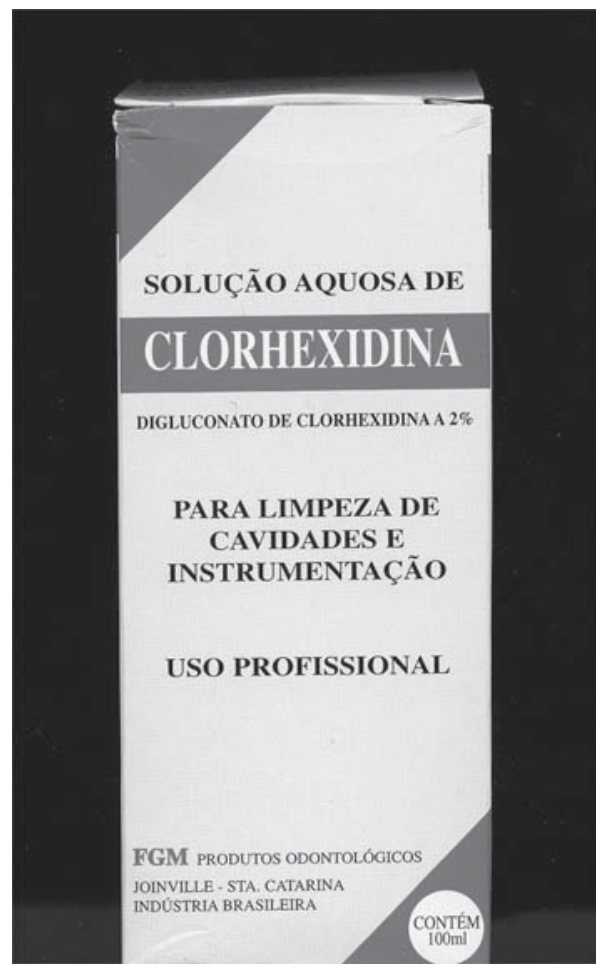

FIGURA 4 - Borrifador com digluconato de clorexidina a $2 \%$.

A análise foi feita, no que diz respeito à total continuidade e nitidez dos ângulos dos três sulcos reproduzidos nos corpos-de-prova, em função da desinfecção química, no período inicial, trinta dias e sessenta dias. Para avaliação deste teste, a classificação utilizada foi estabelecida com escores variando de 0 a 2, de acordo com Goiato et al. ${ }^{9}$ (1999), em que:

0 - reprodução total de dois dos três sulcos;

1 - reprodução total dos 3 sulcos, sem nitidez dos ângulos;

2 - reprodução total dos 3 sulcos, com nitidez dos ângulos.

\section{AnÁlise Estatística}

Os dados obtidos, no teste de alteração dimensional linear, foram submetidos à análise de variância e as médias das repetições de cada grupo, ao teste de Tukey, em nível de 5\% de probabilidade.

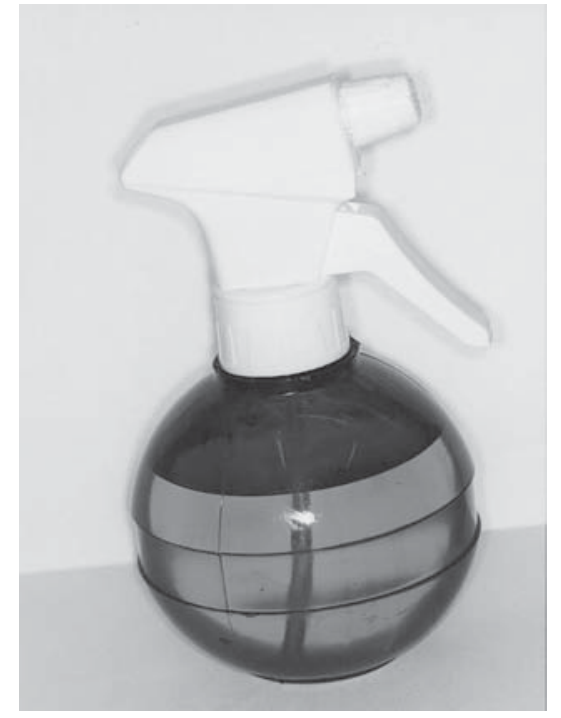

\section{Resultado}

\section{Resultados da alteração dimensional linear}

Resultados obtidos para o silicone Silastic 732 R.T.V.

Nas Tabelas 1, 2 e 3 e Figuras 5, 6 e 7 a seguir, estão demonstrados os valores médios da alteração dimensional linear do silicone Silastic 732 R.T.V., em função da desinfecção química, em todos os períodos de exposição ao meio ambiente.

Após a análise dos resultados do silicone $\mathrm{Si}$ lastic 732 R.T.V., pôde-se observar que todos os grupos apresentaram contração numérica no período inicial, em relação à matriz metálica (Tabela 1 e Figura 5). A desinfecção química somente alterou estatisticamente o grupo Silastic com maquiagem, independentemente do tempo de exposição ao meio ambiente (Tabelas 1, 2 e 3 e Figu$\operatorname{ras} 5,6$ e 7 ). 
Guiotti AM, Goiato MC

SILICONES PARA PRÓTESES FACIAIS: EFEITO DA DESINFECÇÃO QUÍMICA SOBRE DIMENSÃO E SUPERFÍCIE - PARTE II

Tabela 1 - Valores médios da alteração dimensional linear (\%) do silicone Silastic 732 R.T.V., nos diferentes grupos, sem desinfecção química e com desinfecção química, no período inicial

\begin{tabular}{c|cc}
\hline SILICONE & SEM DESINFECÇÃO & COM DESINFECÇÃO \\
\hline Silastic Incolor & $-0,136 \mathrm{a}, \mathrm{B}$ & $-0,120 \mathrm{a}, \mathrm{B}$ \\
Silastic com Maquiagem & $-0,064 \mathrm{a}, \mathrm{A}$ & $-0,120 \mathrm{~b}, \mathrm{~B}$ \\
Silastic com Óxido de ferro & $-0,048 \mathrm{a}, \mathrm{A}$ & $-0,064 \mathrm{a}, \mathrm{A}$ \\
\hline
\end{tabular}

Nota: Médias seguidas da mesma letra minúscula na linha e maiúscula na coluna não diferem estatisticamente entre si em nível de 5\% de probabilidade $(\mathrm{p}<0,05)$, pelo Teste de Tukey.

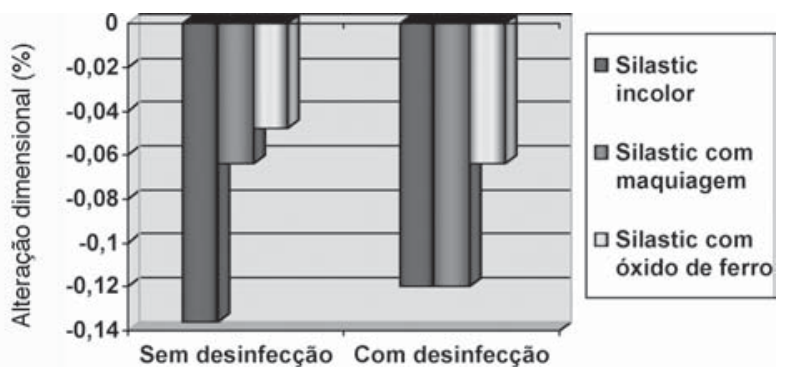

FIGURA 5 - Gráfico dos valores médios da alteração dimensional linear (\%) do silicone Silastic 732 R.T.V., nos diferentes grupos, sem desinfecção química e com desinfecção química, no período inicial.

Tabela 2 - Valores médios da alteração dimensional linear (\%) do silicone Silastic 732 R.T.V., nos diferentes grupos, sem desinfecção química e com desinfecção química, após 30 dias

\begin{tabular}{c|cc}
\hline SILICONE & SEM DESINFECÇÃO & COM DESINFECÇÃO \\
\hline Silastic Incolor & $-0,168 \mathrm{a}, \mathrm{B}$ & $-0,152 \mathrm{a}, \mathrm{B}$ \\
\hline Silastic com Maquiagem & $-0,072 \mathrm{a}, \mathrm{A}$ & $-0,160 \mathrm{~b}, \mathrm{~B}$ \\
Silastic com Óxido de ferro & $-0,048 \mathrm{a}, \mathrm{A}$ & $-0,088 \mathrm{a}, \mathrm{A}$ \\
\hline
\end{tabular}

Nota: Médias seguidas da mesma letra minúscula na linha e maiúscula na coluna não diferem estatisticamente entre si em nível de 5\% de probabilidade $(\mathrm{p}<0,05)$, pelo Teste de Tukey.

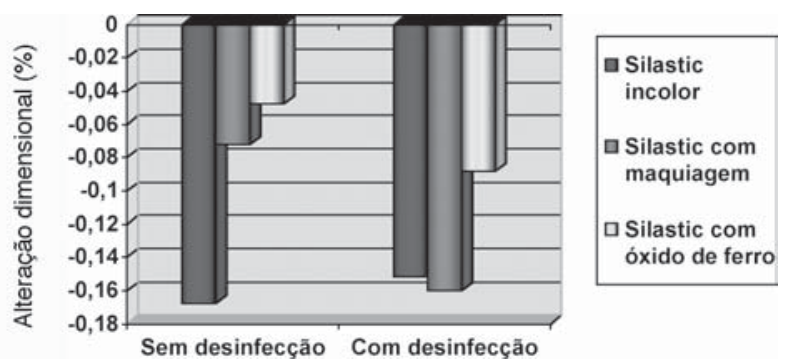

FIGURA 6 - Gráfico dos valores médios da alteração dimensional linear (\%) do silicone Silastic 732 R.T.V., nos diferentes grupos, sem desinfecção química e com desinfecção química, após 30 dias. 
Guiotti AM, Goiato MC

SILICONES PARA PRÓTESES FACIAIS: EFEITO DA DESINFECÇÃO QUÍMICA SOBRE DIMENSÃO E SUPERFÍCIE - PARTE II

Tabela 3 - Valores médios da alteração dimensional linear (\%) do silicone Silastic 732 R.T.V., nos diferentes grupos, sem desinfecção química e com desinfecção química, após sessenta dias

\begin{tabular}{c|cc}
\hline SILICONE & SEM DESINFECÇÃO & COM DESINFECÇÃO \\
\hline Silastic Incolor & $-0,192 \mathrm{a}, \mathrm{B}$ & $-0,176 \mathrm{a}, \mathrm{B}$ \\
Silastic com Maquiagem & $-0,096 \mathrm{a}, \mathrm{A}$ & $-0,184 \mathrm{~b}, \mathrm{~B}$ \\
Silastic com Óxido de ferro & $-0,088 \mathrm{a}, \mathrm{A}$ & $-0,112 \mathrm{a}, \mathrm{A}$ \\
\hline
\end{tabular}

Nota: Médias seguidas da mesma letra minúscula na linha e maiúscula na coluna não diferem estatisticamente entre si em nível de 5\% de probabilidade, pelo Teste de Tukey.

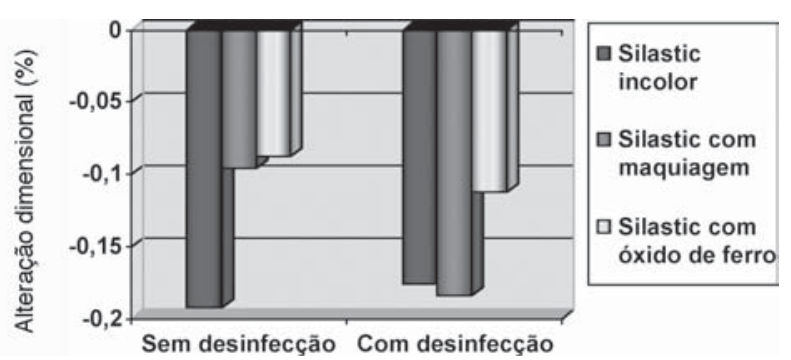

FIGURA 7 - Gráfico dos valores médios da alteração dimensional linear (\%) do silicone Silastic 732 R.T.V., nos diferentes grupos, sem desinfecção química e com desinfecção química, após sessenta dias.

\section{Resultados da manutenção da reprodução de detalhes}

$\mathrm{Na}$ Tabela 4, estão apresentados os resultados da reprodução de detalhes do silicone, em função da desinfecção química, de acordo com a classificação: grau 0 (reprodução total de dois dos três sulcos); grau 1 (reprodução total dos três sulcos, sem nitidez dos ângulos) e grau 2 (reprodução to- tal dos três sulcos, com nitidez dos ângulos) (GOIATO et al. $\left.{ }^{9}, 1999\right)$.

Após a análise dos resultados da manutenção da reprodução de detalhes, pôde-se observar, na lupa estereoscópica Olympus Tokyo, com baixo ângulo de iluminação, num aumento de 13 vezes, que todos os grupos do silicone reproduziram o grau 2, independentemente da ação da desinfecção química (Figuras 8, 9 e 10).

Tabela 4 - Avaliação classificatória obtida no teste de manutenção da reprodução de detalhes do silicone Silastic 732 R. T. V., em função da desinfecção química em relação ao número de sulcos reproduzidos e nitidez dos ângulos

\begin{tabular}{l|ccc}
\hline & \multicolumn{3}{|c}{ GRAU DE CLASSIFICAÇÃO } \\
\hline SILICONE & PERÍODO INICIAL & 30 DIAS & 60 DIAS \\
\hline Silastic Incolor & 2 & 2 & 2 \\
\hline Silastic com maquiagem & 2 & 2 & 2 \\
\hline Silastic com óxido de ferro & 2 & 2 & 2 \\
\hline
\end{tabular}


Guiotti AM, Goiato MC

SILICONES PARA PRÓTESES FACIAIS: EFEITO DA DESINFECÇÃO QUÍMICA SOBRE DIMENSÃO E SUPERFÍCIE - PARTE II
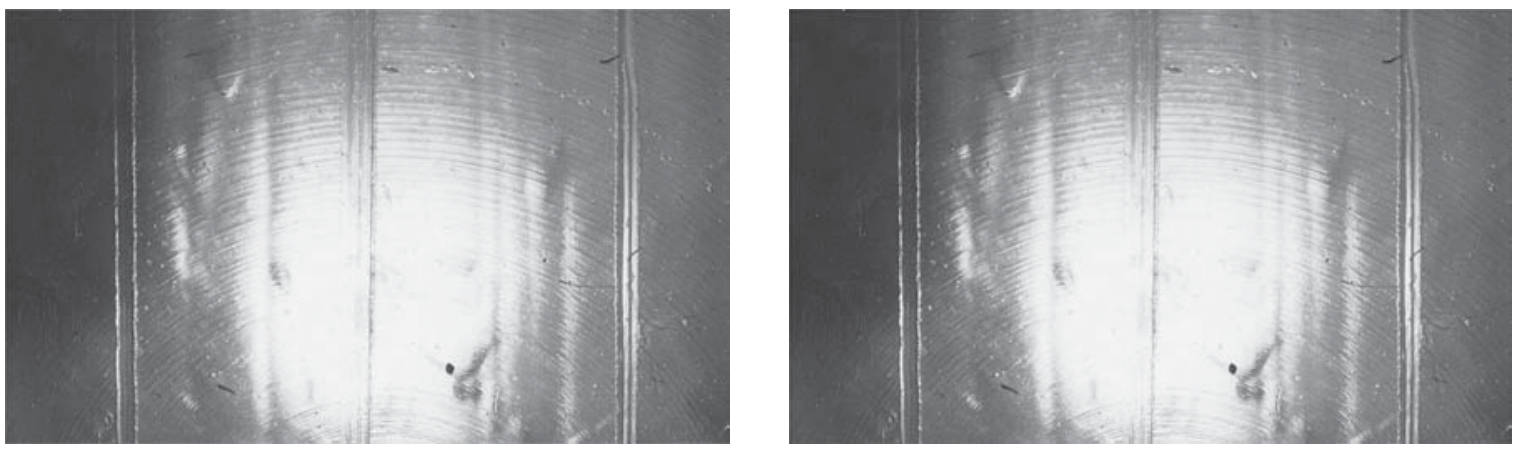

FIGURA 8 - Fotomicroscopias dos corpos-de-prova do silicone Silastic 732 R.T.V. incolor, sem (A) e com desinfecção química (B), no período inicial. (Aumento de $13 x$ ).
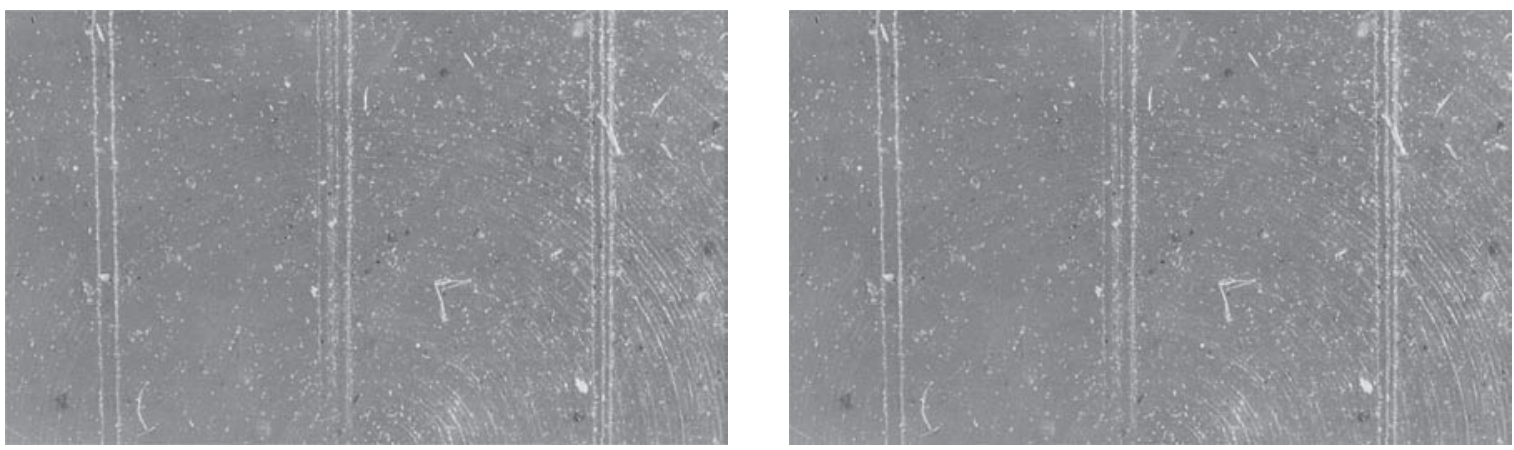

FIGURA 9 - Fotomicroscopias dos corpos-de-prova do silicone Silastic 732 R.T.V. pigmentado, sem (A) e com desinfecção química (B), após 30 dias. (Aumento de 13x).
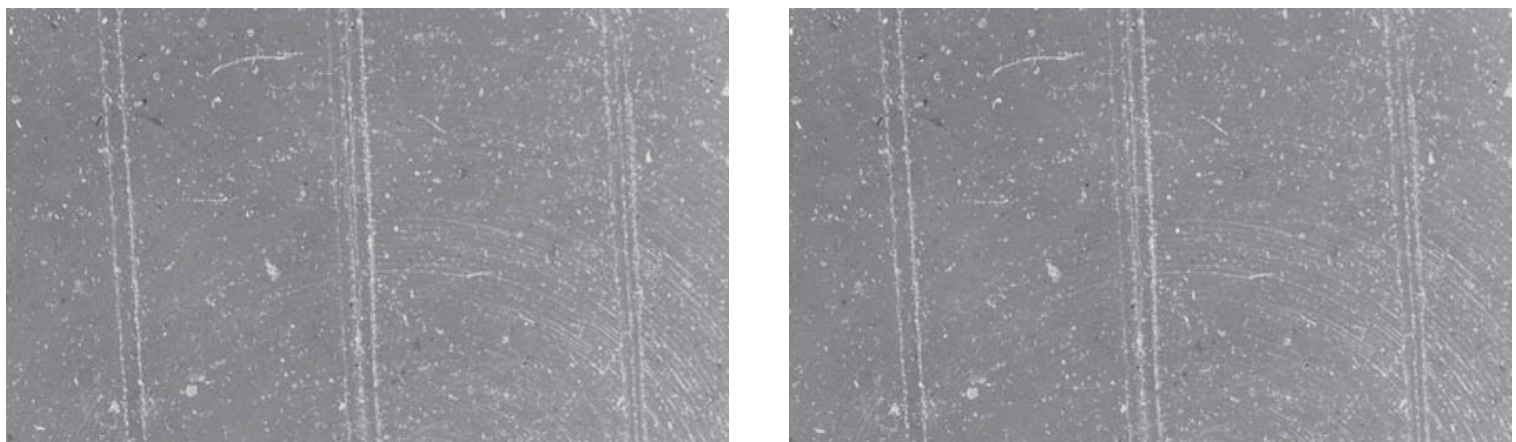

FIGURA 10 - Fotomicroscopias dos corpos-de-prova do silicone Silastic 732 R.T.V. pigmentado, sem (A) e com desinfecção química (B), após sessenta dias. (Aumento de 13x). 


\section{Dıscussão}

Requisitos importantes são exigidos dos materiais para próteses faciais afim de que eles possam cumprir adequadamente suas finalidades, como os citados por Bulbulian ${ }^{6}$ (1945) e referendados por inúmeros autores. Embora existam muitos trabalhos analisando as propriedades físicas e mecânicas dos materiais para prótese facial, preocupamonos, principalmente, em analisar dois requisitos a estabilidade dimensional e a manutenção da reprodução de detalhes sob influência da desinfecção química do silicone, devido à escassez de trabalhos na literatura específica abordando esses dois requisitos. Como observado em estudo anterior, o silicone Silastic 732 R.T.V., mostrou-se como um bom material para prótese facial, não sendo afetado significativamente pelo tempo de exposição ao meio ambiente, e a pigmentação melhorou o seu comportamento. Para completar o estudo das propriedades do silicone Silastic 732 R.T.V., o objetivo desta pesquisa foi o de analisar o efeito de mais uma variável - a influência da desinfecção química sobre a estabilidade dimensional e a manutenção de detalhes desse silicone.

\section{Alteração dimensional linear do silicone silastic 732 R.T.V.}

Conforme mostram as Tabelas 1, 2 e 3 e Figuras 5, 6 e 7, os dados obtidos evidenciaram que o silicone para uso facial Silastic 732 R.T.V. apresentou alteração dimensional linear negativa de presa (contração), quando comparado às dimensões C e D da matriz metálica (25 mm). Phillips ${ }^{21}$ (1993) afirmou que todos os elastômeros sofrem contração durante a polimerização. Esses valores iniciais foram considerados como controle para a análise dos demais valores obtidos sob influência da desinfecção química. De acordo com Anusavice ${ }^{2}$ (1998), a reação de polimerização das siliconas por condensação continua mesmo após a presa clínica, havendo uma contração de polimerização contínua, devido à formação de um sub-produto volátil, o álcool etílico (MIRANDA ${ }^{17}$, 1984; MCELROY et al. $\left.{ }^{16}, 1985\right)$. No caso do silicone analisado neste estudo, há a liberação de ácido acético como subproduto da reação de polimerização.

O uso da desinfecção química (Tabelas 1, 2 e 3 e Figuras 5, 6 e 7) não promoveu nenhuma alteração dimensional linear negativa estatisticamente significativa nos corpos-de-prova do silicone $\mathrm{Si}$ - lastic 732 R.T.V., nos diferentes períodos, com exceção dos pigmentados com maquiagem. Este fato ocorreu provavelmente devido à interação da clorexidina com os pigmentos de maquiagem, na superfície dos corpos-de-prova, dissolvendo-os e possibilitando uma maior contração, devido à diminuição da quantidade de carga e aumento da concentração do polímero. De acordo com Rowe \& Forrest $^{27}$ (1978), considerados dois dos primeiros autores a se preocuparem com a ação da desinfecção química sobre a estabilidade dimensional dos materiais de moldagem, mostraram que a solução de clorexidina, atuando na silicona por condensação, em diferentes períodos de imersão (30 segundos, 1 minuto, 5 minutos e 24 horas) não promoveu nenhuma alteração dimensional nos corposde-prova confeccionados. Langenwalter et al. ${ }^{12}$ (1990) também verificaram que os desinfetantes não produziram alteração dimensional linear significante sobre os materiais elastoméricos ensaiados.

Segundo Phillips ${ }^{21}$ (1993) e Anusavice ${ }^{2}$ (1998), devido ao fato de os polímeros de silicone serem líquidos, sílica coloidal ou micropartículas de óxidos metálicos são adicionadas como carga para formar uma pasta. A seleção e o pré-tratamento dispensado às cargas são de extrema importância, uma vez que os silicones têm um baixo nível de energia coesiva e, portanto, uma interação molecular fraca (carga-polímero). O tamanho das partículas de carga deve estar dentro de certos limites, entre 5 e $10 \mu \mathrm{m}$. Partículas pequenas tendem a se agregar, mas as maiores se separam do polímero, não contribuindo como agente de reforço do material. Provavelmente, as partículas de pó de maquiagem sejam maiores do que as partículas de óxido de ferro e dessa forma, são mais facilmente separadas do polímero, quando sob a ação da clorexidina.

Entretanto, a contração ocorrida nos corpos-deprova do silicone Silastic 732 R.T.V. pigmentado com maquiagem, se enquadra na recomendação da especificação $\mathrm{n}^{0} 19$ da A.D.A. ${ }^{23}$, na qual a contração não deve ultrapassar 1\%, por 24 horas.

Portanto, em nosso estudo, constatou-se que a clorexidina pode ser utilizada como um eficiente agente de desinfecção química, não promovendo alterações significativas ao material, apesar da alteração dimensional ocorrida com o grupo pigmentado com maquiagem, sob efeito da desinfecção. 
Manutenção da reprodução de detalhes dos silicones Silastic 732 R.T.V.

A capacidade de reprodução de detalhes dos materiais para prótese facial é importante para a caracterização e, conseqüentemente para a estética da prótese. Estes materiais têm que ser capazes de reproduzir e manter tais detalhes, como: sulcos de expressão, rugas, poros e outras características próprias da pele humana; tornando a prótese mais imperceptível àqueles que observam seu portador.

Quanto à manutenção da reprodução de detalhes, os resultados mostraram que todos os grupos, reproduziram o grau 2 (Tabela 4), quando observados na lupa estereoscópica Olympus Tokyo, com baixo ângulo de iluminação, em aumento de 13 vezes, independentemente da desinfecção química. Este grau 2 significa que todos os corpos-deprova reproduziram totalmente os 3 sulcos, com nitidez dos ângulos, de acordo com a classificação de Goiato et al. ${ }^{9}, 1999$.

Esses resultados confirmam as observações de diversos autores (REISBICK \& MATYAS ${ }^{22}$, 1975; CLANCY et al. ${ }^{7}, 1983$; GOIATO et al. ${ }^{9,10}, 1999$, 2001), quando verificaram que as siliconas (para moldagem) mostraram excelente capacidade de reprodução de detalhes, ao reproduzirem sulcos com até $20 \mu \mathrm{m}$ de largura. Resultados semelhantes foram obtidos por Storer \& McCabe ${ }^{29}$ (1981), Werner et al. ${ }^{30}(1992)$ e Goiato et al. ${ }^{9,10}(1999,2001)$, quando verificaram que a imersão de moldes de silicona (para moldagem), em diversos desinfetantes, não alterou os detalhes produzidos pela moldagem.

De acordo com Peutzfeldt \& Asmussen ${ }^{20}$ (1989), o período de contato do desinfetante com o molde de materiais de moldagem deve ser suficientemente controlado para não alterar a fidelidade obtida e a textura da superfície do molde.
Assim, estudando o efeito de soluções desinfetantes de moldes dentários, Rowe \& Forrest ${ }^{27}$ (1978) sugeriram que a desinfecção deva ser feita com spray ou solução de clorexidina, por 1 minuto, condição suficiente para reduzir o nível de contaminação bacteriana sem, contudo, comprometer a fidelidade de reprodução. Budtz-Jorgensen ${ }^{5}$ (1979) ressaltou a utilização de digluconato de clorexidina para a desinfecção de próteses e sua eficiência na redução de placa bacteriana e melhoria da mucosa em pacientes com estomatite protética.

\section{Conclusão}

Por meio dos resultados obtidos e analisados neste estudo, concluiu-se que:

- O silicone Silastic 732 R.T.V. apresentou propriedades satisfatórias, não sendo afetado significativamente pelo tempo de exposição ao meio ambiente, e a pigmentação melhorou o seu comportamento, como observado em estudo prévio;

- neste estudo, a desinfecção química apenas teve influência estatisticamente significativa sobre o grupo Silastic com maquiagem, para todos os tempos de exposição, porém esta contração foi muito pequena (inferior à $0,5 \%$ ), se enquadrando na recomendação da especificação n $^{\circ} 19$ da A.D.A.;

- pôde-se concluir que a clorexidina não promoveu alterações significativas sobre as propriedades analisadas no material, apesar da alteração dimensional ocorrida com o grupo pigmentado com maquiagem, sob efeito da desinfecção;

- A fidelidade e manutenção da reprodução de detalhes obtida para todos os corpos-de-prova não foi influenciada pela ação da desinfecção química.

\section{Abstract}

The purpose of this study was to analyse the influence of chemical disinfection with $2 \%$ chlorhexidine-based solution about dimensional changing and maintenance of details of a silicone for use in maxillofacial prosthesis. Specimens were fabricated using a matrix, conformed closely to the specifications for non-aqueous, elastomeric dental impression materials established by the Revised American Dental Association $n^{\circ} 19$ and the ISO 4823:1984. Specimens were separated in three groups: control (colourless), pigmented with commercial cosmetic (makeup powders) and pigmented with iron oxid. Specimens were analysed in a comparator microscopic (Carl Zeiss) and stereoscopic loupe. The readings were realized after polymerization of the specimens, and after 
Guiotti AM, Goiato MC

SILICONES PARA PRÓTESES FACIAIS: EFEITO DA DESINFECÇÃO QUÍMICA SOBRE DIMENSÃO E SUPERFÍCIE - PARTE II

30 and 60 days, with and without disinfection. The data were submited to the statistic analysis, by the Tukey's Test, at $5 \%$ level of probability. The results indicated that all groups presented contraction; the chemical disinfection only changed the dimensional stability of the Silastic cosmetic pigmented group; however, this contraction was inferior of the A.D.A. advices. The details were maintained in all specimens, independent of desinfection. We may conclude that chlorhexidine is a good desinfectant agent for facial prosthesis, doesn't promoting changes in the silicone.

\section{UNITERMS}

Maxillofacial prosthesis; silicone elastomers; dental prosthesis, dimensional stability; desinfection

\section{Referências}

1. Andres CJ, Haug SP, Brown DT, Bernal G. Effects of environmental factors on maxillofacial elastomers: Part II: report of survey. J Prosthet Dent 1992 Sept.; 68 (3):519-22.

2. Anusavice KJ. Materiais de moldagem elastoméricos não aquosos. In:___. Phillips materiais dentários. 10.ed. Rio de Janeiro: Guanabara Koogan; 1998. p. 83-106.

3. Azambuja TWF, Padilha DMP, Bercini F, Burzlaff JB, Puricelli E. Face: possibilidade de reconstrução protética (Relato de um caso). Rev Fac Odontol Porto Alegre 1994 Dez.; 35 (2):18-9.

4. Barnhart GW. A new material and technic in the art of somatoprosthesis. J Dent Res 1960 july./aug.; 39 (4):836-44.

5. Budtz-Jorgensen E. Materials and methods for cleaning dentures. J Prosthet Dent 1979 Dez; 42 (6):619-23.

6. Bulbulian AH. Facial prosthesis. Philadelphia: Saunders; 1945. $241 \mathrm{p}$.

7. Clancy JMS, Scandrett FR, Ettinger RL. Long term dimensional stability of three current elastomers. J Oral Rehabil 1983 Jul.; 10 (4):325-33.

8. Denardi BB. O uso da clorexidina na prática odontológica. Rev Assoc Paul Cir Dent 1994 mar./abr.; 48 (2):1279-84.

9. Goiato MC, Consani S, Goes MF, Sinhoretti MAC. Efeitos dos desinfetantes sobre a estabilidade dimensional e na manutenção de detalhes das siliconas. Rev Bras Prot Clin \& Lab 1999; 1 (2): 117-22.

10. Goiato MC, Guiotti AM, Gennari Filho H, Fajardo RS, Assunção WG. Influência da desinfecção química na alteração dimensional linear e manutenção dos detalhes dos materiais elastoméricos de registro de mordida. Rev Bras Prot Clin \& Lab 2001 mar./abr.; 3 (12):117-25.

11. Ishigami T, Tanaka Y, Kishimoto Y, Okada M. A facial prosthesis made of porcelain fused to metal: a clinical report. J Prosthet Dent 1997Jun.; 77 (6):564-7.

12. Langenwalter EM, Aquilino SA, Turner KA. The dimensional stability of elastomeric impression materials following disinfection. J Prosthet Dent 1990 Mar.; 63 (3):270-6.

13. Larson E. Guideline for use topical antimicrobial agents. Am J Infect Control 1988 Dez.; 16 (6):253-66.

14. Lemon JC, Chambers MS, Jacobsen ML, Powers JM. Color stability of facial prostheses. J Prosthet Dent 1995 Dez.; 74 (6):6138 .

15. Lewis DH, Castleberry DJ. An assessment of recent advances in external maxillofacial materials. J Prosthet Dent 1980 Abr.; 43 (4):426-32.

16. McElroy TH, Guerra ON, Lee SA. Acetic acid vapor levels associated with facial prosthetics. J Prosthet Dent 1985 Jan.; 53 (1): 86-7.
17. Miranda CC. Materiais de moldagem. Elastômeros: variações dimensionais. In:__. Atlas de reabilitação bucal. São Paulo: Ed. Santos; 1984. p. 309-39.

18. Moore DJ, Glaser ZR, Tabacco MJ, Linebaugh, MG. Evaluation of polymeric materials for maxillofacial prosthetics. J Prosthet Dent 1977 Sept.; 38 (3):319-26.

19. Neves ACC, Villela LC. Desenvolvimento de uma escala em silicona para tons de pele humana. Rev Odontol Univ São Paulo 1998 jan./mar.; 12 (1):57-63.

20.Peutzfeldt A, Asmussen E. Effect of disinfecting solutions on surface texture of alginate and elastomeric impressions. Scand J Dent Res 1990; 98 (1):74-81.

21. Phillips RW. Elastômeros para moldagem. In:__. Skinner materiais dentários. 9.ed. Rio de Janeiro: Guanabara Koogan; 1993. p. 77-90.

22. Reisbick MH, Matyas J. The accuracy of highly filled elastomeric impression materials. J Prosthet Dent 1975 Jan.; 33 (1):6772.

23. Revised American Dental Association Specification no 19 for Nonaqueous, Elastomeric Dental Impression Materials. J Am Dent Assoc 1977 Abr.; 94 (4):733-41.

24. Revision of ISO 4823:1984. International Standard Organization. Dental elastomeric impression materials. Genebra; 1989. p.iii, 1-21.

25. Rezende JR, Maringoni Filho N. Novo material para prótese facial. Quintessência 1979 Maio; 6 (5):73-8.

26. Rezende JRV. Alterações de dimensão linear e de dureza Shore A em função do envelhecimento e da inclusão de tela de "nylon". Rev Fac Odontol S. Paulo 1975 jan./jun.; 13 (1):45-54.

27. Rowe AHR, Forrest JO. Dental impressions: the probability of contamination and a method of disinfection. Br Dent J 1978 Sept.; 145 (6): $184-6$

28. Schaaf NG. Color characterizing silicone rubber facial prostheses. Int Dent J 1970 Aug.; 24 (2):198-202.

29. Storer R, McCabe JF. An investigation of methods available for sterilising impressions. Br Dent J 1981 Oct.; 151 (7):217-9.

30. Werner SM, Schaly C, Suffert LW. Efeito de desinfetantes sobre a manutenção de detalhes de impressões dentárias. Rev Paul Odontol 1992 maio/jun.; 14 (3):22-7.

Entrada: 07/08/03 Aprovado: 18/11/03

Aimée Maria Guiotti Rua Celso Spínola Castro, 400 - Jd. Morumbi CEP. 15090-200 - São José do Rio Preto - SP. mailto:goiato@foa.unesp.br 